\title{
Obstetric violence in South Africa
}

Abusive practices in obstetric care settings have been reported in the USA since the 1950s. However, it is only since the 2000s that this issue has been identified as a worldwide health and social problem. ${ }^{[1]}$ The mistreatment of women and girls during childbirth has been documented in a range of global contexts, including high-income countries $^{[2-3]}$ and middle- to low-income countries. ${ }^{[4-6]}$ There has recently been growing international attention to this problem, ${ }^{[7,8]}$ and it has been recognised that abusive treatment is connected to poor uptake of maternity services and poor maternal and infant health outcomes in some settings. For a long time, the importance of respectful and dignified care during labour and childbirth has been a 'blind-spot' in global health agendas, ${ }^{[7]}$ but calls for action and accountability are now becoming difficult to ignore. ${ }^{[5,7,8]}$ Current debates and global activism are increasingly drawing on the concept of 'obstetric violence' to contextualise and address patterns of mistreatment of women and girls during labour and childbirth. This editorial introduces this concept and explores its potential relevance in the South African (SA) context.

\section{Introducing the concept of obstetric violence}

A range of terms have been used to describe violence against women and girls during labour and birth, including childbirth abuse, 'birth rape, mistreatment, and most recently obstetric violence. A wide range of problematic practices have been associated with these terms, including neglect, verbal and emotional abuse, physical abuse, sexual abuse, lack of confidential and consensual care, and the inappropriate, non-evidence-based use of medical interventions, including routine episiotomies, routine inductions, preventing labour companions, and unnecessary caesarean sections. ${ }^{[9,10]}$ The concept of obstetric violence emerged in the 2000s in Latin America and Spain as an extension of the activist struggle to humanise and demedicalise childbirth and empower women and girls during pregnancy, labour and birth. It emerged as a legal term in Venezuela in 2007 and was adopted by Argentina in 2009 and by Mexico in 2014. Perpetrators of acts of obstetric violence are subject to criminal liability in these countries, which usually amounts to a fine and a signed acknowledgement of wrongdoing on the part of the practitioner and/or the institution. In Venezuelan law, published in Article 15 of the 'Organic Law on the Right of Women to a Life Free of Violence', obstetric violence is included as one of 19 different forms of punishable violence against women and is defined as:

'... the appropriation of the body and reproductive processes of women by health personnel, which is expressed as dehumanized treatment, an abuse of medication, and to convert the natural processes into pathological ones, bringing with it a loss of autonomy and the ability to decide freely about their bodies and sexuality, negatively impacting the quality of life of women. ${ }^{[9]}$

The use of the controversial term 'obstetric violence' over more neutral labels such as 'mistreatment' is part of a deliberate move to confront problematic practices, which have often been hidden, invisible and unacknowledged, as forms of violence. For activists and practitioners in Latin American contexts, aggressive, humiliating and disrespectful treatment of women and girls during labour and birth is part of broader and entrenched gender violence and social inequalities of race, class, age and ethnicity. Medical interventions (most notably routine episiotomies and unnecessary caesarean sections) that are used excessively are also defined as examples of 'obstetric violence'.

\section{Lack of accountability for abuses in the SA context}

Not surprisingly, medical practitioners have been hostile to the concept of obstetric violence and its legal implications in the Latin American context, fearing that it potentially criminalises routine medical treatment. ${ }^{[5]}$ The move to tackle abuse in maternal healthcare settings by adopting legal routes should, however, be recognised as partly the result of the failure of the medical establishment to confront these issues and hold healthcare professionals and institutions of care accountable for unacceptable practices. This is the case in Latin America and also increasingly in SA. As a result, calls for legal action and the criminalisation of abusive practices by healthcare professionals are now gaining ground in the SA context. ${ }^{[11]}$ While it is true that the roots of abusive treatment (in SA and other contexts) are complex, including health system inadequacies, an insufficient emphasis on an ethics of care in midwifery training, poor working conditions, healthcare professional overload and historical legacies of inequalities, there is also no excuse for failure to hold individuals and institutions accountable for practices that dehumanise, degrade and cause harm to women and girls in some of their most vulnerable moments (i.e. labour and childbirth). Efforts to change institutional cultures that condone medicalised forms of violence and abuse need to be led by medical practitioners, professional associations and institutional boards.

\section{A form of gender violence?}

In the medical literature, debates about mistreatment are often predominantly framed in relation to quality-of-care issues and the failure of evidence-based obstetric practice. Often the assumption is that informing and training practitioners about evidence-based medicine (i.e. the benefits of labour companions) is enough to change practices on the ground. In the SA context in particular, achieving changes in practice has proved extremely difficult. ${ }^{[12]}$ Reports of abusive mistreatment of women and girls in obstetric contexts date back to $1998,{ }^{[13]}$ yet little seems to have changed almost 20 years later, with recent research finding the same patterns of mistreatment in public sector facilities. ${ }^{[6]}$ There is no doubt that there are significant structural impediments to changing practices (i.e. spatial configurations of obstetric facilities that discourage privacy and women's right to a labour companion). At the same time, we need to acknowledge the abusive treatment of women and girls in maternity services as a form of gender violence ${ }^{[5,8,14]}$ that reflects the broader societal devaluation of women and girls and the normalisation of violence against them (particularly marginalised and impoverished women and girls). Violence in obstetric contexts in SA is multilayered and complicated by the fact that it includes both individual acts of abuse and structural components such as degrading spatial configurations that lead to lack of privacy and impede the use of labour companions. We need to address both obvious forms of violence where there is a clear individual 'perpetrator' (i.e. physical abuse of patients and intentional emotional abuse) and structural forms of violence (demeaning attitudes towards poor women and girls, authoritative power of obstetric knowledge, infrastructural problems) that create the conditions for individual abuse.

SA could learn a great deal from what is happening in Latin America and Spain, where activism and action against abusive treatment during labour and childbirth have been framed within 
a broader rhetoric of women's rights to lives free from all forms of violence and abuse. In these contexts, high rates of medicalisation are also recognised as sources of abuse. ${ }^{[5,9]}$ In the SA context, there has been a lack of attention to potential abuses in private sector facilities, with the predominant assumption that mistreatment and abuse is only a problem in public sector maternity services. This is surprising, given that the private sector in SA has one of the highest rates of caesarean section in the world, with estimates ranging between $40 \%$ and $82 \% .^{[15,16]}$ Such estimates are far above the rate of $15 \%$ recommended by the World Health Organization and raise concerning questions about levels of unnecessary medical intervention in private sector obstetrics in SA. The silence on this issue is itself worrying, and the time is ripe for further investigation and debate regarding practices in the private sector.

\section{Conclusions}

Regardless of the roots of abusive treatment, it is important to strive for accountability on all levels - in respect of the state, medical institutions, training programmes and individual practitioners. The use of violence in the form of coercive practices, physical and emotional abuse, lack of consent, intentional humiliation, the withholding of medical attention and care during labour and childbirth as a form of punishment, and the unnecessary use of medical interventions are unacceptable and reflect entrenched systems of gender and class marginalisation in SA. The medical establishment needs to recognise forms of abuse during labour and childbirth as more than the actions of a few misinformed individuals and to address wider systemic sexism and classism in medical training, established protocols and attitudes towards childbearing women and girls.

\section{Rachelle Joy Chadwick}

Gender Studies Section, School of African and Gender Studies, Anthropology and Linguistics, Faculty of Humanities, University of Cape Town, South Africa

rachelle.chadwick@uct.ac.za

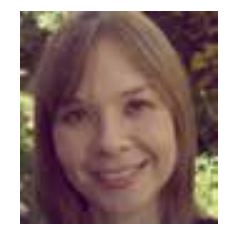

1. D’Oliveira A, Diniz S, Schraibe, L. Violence against women in health-care institutions: An emerging problem. Lancet 2002;359(9318):1681-1685. DOI:10.1016/S0140-6736(02)08592-6

2. Schroll, A, Kjaergaard, H, Midtgaard, J. Encountering abuse in health care: Lifetime experiences in postnatal women - a qualitative study. BMC Preg Childbirth 2013;13(74):1-11. DOI: 10.1186/1471-2393-13-74

3. Swahnberg K, Thapar-Björkert S, Berterö C. Nullified: Women's perceptions of being abused in health care. J Psychosom Obstet Gynaecol 2007;28(3):161-167. DOI:10.1080/01674820601143211

4. D’Ambruoso L, Abbey M, Hussain J. Please understand when I cry out in pain: Women's accounts of maternity services during labour and birth in Ghana. BMC Public Health 2005;5(140):1-11. DOI:10.1186/1471-2458-5-140

5. Dixon L. Obstetrics in a time of violence: Mexican midwives critique routine hospital practices. Med Anthrop Quart 2015;29(4):437-454.

6. Chadwick R, Cooper D, Harries J. Narratives of distress about birth in South African public maternity settings: A qualitative study. Midwifery 2014;30(7):862-868. DOI:10.1016/j.midw.2013.12

7. Freedman L, Kruk M. Disrespect and abuse of women in childbirth: Challenging the global quality and accountability agendas. Lancet 2014;384(9948):e42-e44. DOI:10.1016/S0140-6736(14)60859-X

8. Jewkes R, Penn-Kekana L. Mistreatment of women in childbirth: Time for action on this important dimension 8. Jewkes R, Penn-Kekana L. Mistreatment of women in childbirth: Time for action on this important
of violence against women. PLoS Med 2015;12(6):e1001849. DOI:10:1371/journal/pmed.1001849

of violence against women. PLoS Med 2015;12(6):e1001849. DOI:10:1371/journal/pmed.1001849
9. Pérez D'Gregorio R. Obstetric violence: A new legal term introduced in Venezuela. Int J Gynecol 9. Pérez D'Gregorio R. Obstetric violence: A new legal term i
Obstet 2010;111(3):201-202. DOI:10.1016/j.ijgo.2010.09.002

10. Bohren M, Vogel J, Hunter E, et al. The mistreatment of women during childbirth in health facilities globally: A mixed-methods systematic review. PLoS Med 2015;12(6):e1001847. DOI:10.1371/journal. pmed. 1001847

11. Pickles C. Eliminating abusive 'care': A criminal law response to obstetric violence in South Africa. SA Crime Quart 2015;54(1):5-16. DOI:10.4314/sacq.v5i1.1

12. Brown H, Hofmeyr J, Nikodem C, Smith H, Garner P. Promoting childbirth companions in South Africa: A randomised pilot study. BMC Med 2007;5(7):1-8. DOI:10.1186/1741-7015-5-7

13. Jewkes R, Abrahams N, Mvo Z. Why do nurses abuse patients? Reflections from South African obstetric services. Soc Sci Med 1998;47(11):1781-1795. DOI:10.1016/S0277-9536(98)00240-8

4. Smith-Oka V. Microagressions and the reproduction of social inequalities in medical encounters in Mexico. Soc Sci Med 2015;143:9-16. DOI:10.1016/j.socscimed.2015.08

15. Naidoo R, Moodley J. Rising rates of caesarean sections: An audit of caesarean sections in a specialist private practice. S Afr Fam Pract 2009;51(3):254-258. DOI:10.1080/20786204.2009.10873857

private practice. S Afr Fam Pract 2009;51(3):254-258. DOI:10.1080/20786204.2009.10873857
16. Rothberg A, Macleod H. Private-sector caesarean sections in perspective. S Afr Med J 2005;95(4):257-260.

S Afr Med J 2016;106(5):423-424. DOI:10.7196/SAMJ.2016.v106i5.10708 